\title{
1
}

\section{Building and modifying the team for growth}

\section{THE IMPORTANCE OF TEAMS IN THE SUCCESS OF SOCIAL STARTUPS}

Despite the plethora of press coverage given to "star" entrepreneurs such as Elon Musk ${ }^{1}$ (founder of SpaceX, Tesla and Solar City) and Steve Jobs² (founder of Apple), research shows that successful entrepreneurial firms are predominately founded by teams, not lone wolf entrepreneurs. In fact, across ten different research studies, 70 percent of all startups were founded by teams, ${ }^{3}$ such that "the entrepreneur in entrepreneurship is more likely to be plural." ${ }^{\prime 4}$ In this chapter, we take a close look at what composes a well-functioning team for the social startup. This includes understanding what makes for a good founding team, ${ }^{5}$ with a distinct focus on the first five years of a social startup's life.

As a basis for this book and chapter, we held detailed, in-depth interviews with founders of eight social enterprises (SEs) that scaled significantly post-founding, ${ }^{6}$ including: Embrace, ${ }^{7}$ Back to the Roots, ${ }^{8}$ Sanergy, ${ }^{9}$ d.light, ${ }^{10}$ World of Good (WOG, since its founding, it has been purchased by eBay), ${ }^{11}$ Kiva, ${ }^{12}$ Revolution Foods ${ }^{13}$ and Fair Trade USA. ${ }^{14}$ These startups were chosen due to their high growth in revenue, employee base, and impact within the social startups' first five years.

Table 1.1 Founding team members

\begin{tabular}{l|c|c|c}
\hline \multicolumn{1}{|c}{ Single Founder } & & Three+ Founders \\
\hline Embrace & & $\mathrm{X}$ & $\mathrm{X}$ \\
\hline Back to the Roots & & & $\mathrm{X}$ \\
\hline Sanergy & & $\mathrm{X}$ & $\mathrm{X}$ \\
\hline d.light & & & \\
\hline World of Good & & $\mathrm{X}$ & \\
\hline Kiva & & $\mathrm{X}$ & \\
\hline Revolution Foods & & & \\
\hline Fair Trade USA & & & \\
\hline
\end{tabular}

Note: As shown in Table 1.1, all companies were founded by a team of at least two, with the exception of Fair Trade USA, which had a single founder in Paul Rice. ${ }^{15}$ 
We then complemented our case-based research, pulling from published research in the fields of strategy, entrepreneurship, social entrepreneurship and management, as well as mainstream publications in entrepreneurship and social entrepreneurship from media sources such as Inc. and Stanford Social Innovation Review.

\section{WHY INVESTORS CHOOSE TEAMS}

In both academic and mainstream literature, it is well known that investors select startup teams and rarely invest in a sole entrepreneur. As the "first" venture capitalist, General George Doriot, ${ }^{16}$ famously said, "I prefer a Grade A entrepreneur and team with a Grade B idea, over a Grade B team with a Grade A idea." ${ }^{17}$ Notable venture capitalist John Doerr ${ }^{18}$ from Kleiner Perkins Caufield and Byers ${ }^{19}$ concurs: "In the world today, there's plenty of technology, plenty of entrepreneurs, plenty of money, plenty of venture capital. What's in short supply is great teams." 20

Partners of the seed stage social venture capital firm, Better Ventures, ${ }^{21}$ also prioritize the quality of the team, in addition to the quality of the investment, such that the startups must have at a minimum two founders, with one of the founders being a "hacker" - or a more technical person - and the other founder serving as a "hustler" - or a more business-oriented person. ${ }^{22}$ In addition to team diversity, Better Ventures' founders are also looking for team commitment. As stated by Better Ventures partner, Wes Selke, "We're looking for intelligence, tenacity, and intentionality - something indicating that they've been thinking about this problem for a really long time and maybe it affected them personally." ${ }^{23}$

Published academic research supports why having a well-functioning team serves as an important investment criterion for funders. First, research has shown that teams manage stress better in comparison to individual founders. ${ }^{24}$ Specifically, research on social startups concludes that sole entrepreneurs are more likely to experience loneliness and higher levels of apprehension around resolving conflicts amongst employees. Lone entrepreneurs are also more likely to suffer from an achievement gap if the startup's performance is not aligned with the founder's aspirations. ${ }^{25}$ Management research has shown that teams perform better in knowledge-intensive fields, ${ }^{26}$ as knowledge sharing enriches the mastery of the entire team, ${ }^{27}$ enabling them to provide more nuanced and thoughtful responses to competitive threats. ${ }^{28}$ Of course, investing in a single individual is also risky for other reasons. For example, if the sole founder should leave the firm, or for whatever reason is no longer effective (e.g. personal illness, etc.), the immediate impact on the firm's performance is outsized in comparison to the impact that one individual's departure might have on a startup founded by a team. ${ }^{29}$

In our specific set of social startups, we see that most are founded by diverse teams and that many of the founders had the opportunity to both incubate the idea, and to get to know each other as teammates, over a period of time while completing their undergraduate or graduate degrees. For example, Back to the Roots was founded by Nikhil Arora and Alejandro Velez who met when they were both undergraduate business majors at UC Berkeley. Similarly, Revolution Foods' co-founders, Kristin Richmond and Kirsten Tobey, met at the start of their MBA at UC Berkeley, and continued to work on their idea throughout both years of their 
MBA program. d.light was co-founded by Sam Goldman and Ned Tozun, who were also both MBA students at Stanford's Graduate School of Business; they, however, came up with the idea for d.light while participating in Stanford Design School's Design for Extreme Affordability course. ${ }^{30}$ While several other engineering co-founders (mechanical and electrical engineers) were also affiliated with d.light in its earliest days, through the same course, they did not stay with the firm long term. Embrace's co-founders also met in Stanford Design School's Design for Extreme Affordability course and were one of the more diverse teams profiled in this book with respect to education and prior work experience. The four original classmates and ultimately co-founders include: Jane Chen, Linus Liang, Naganand Murty and Rahul Panicker. ${ }^{31}$

WOG was co-founded by Priya Haji and Siddharth Sanghvi, ${ }^{32}$ who also met while getting their MBAs at UC Berkeley. Sanergy was co-founded by MBA students who met while at MIT, and they worked on the idea throughout the MBA program. Three co-founders stayed with the startup postgraduation, including: David Auerbach, Lindsay Stradley and Ani Vallabhaneni. Kiva was founded initially by a married couple, Matt Flannery and Jessica Jackley, who were then joined by Premal Shah and Chelsa Bocci; these four co-founders also represented a diverse team. Clearly, larger teams are more likely to have greater diversity than smaller teams, and that is noted, and discussed, in greater detail towards the end of this chapter.

\section{CHARACTERISTICS OF SUCCESSFUL FOUNDING TEAMS}

Given the many benefits of a founding team, we then ask, what does one look for in an ideal team? The popular press ${ }^{33}$ mentions five main factors investors use to evaluate founding teams: (1) talent, (2) mutual respect, (3) experience, (4) adaptability, and (5) a history of working well together. For talent, given the low success rates of startups, founders that hold domain expertise within the same or closely related industry as that of the startup are important and highly valued. Prior research has also shown that having differing expertise across the team leads to better decision-making, but only when this experience heterogeneity is paired with trust; trust mediates the potential conflict that is inherent with high levels of team heterogeneity. ${ }^{34}$ To quote social entrepreneurship scholars:

When people work in teams, they have a better chance of finding the right balance between a vision of change and the operational prowess needed to deliver on that vision. It is rare to find a person who can hold these conflicting trajectories in sync, which is why working in groups with people of different skills - some strategic, some delivery focused - can facilitate change faster. ${ }^{35}$

Trust also ensures that conflict does not move from more task-related conflicts, or differences of opinion, to personal and or relationship conflicts, which can have a more detrimental impact on the team's cohesion in the long run. Cohesion, which relates to how well each team member integrates, prioritizes and self-identifies with the team, is important and has been shown to correlate with better financial performance among startup teams. ${ }^{36}$ Inherently, in any startup there is also conflict due to having too much to do with too few resources, and having 
to perform many different tasks under time constraints. In the face of conflict, two other factors in addition to trust come into play: having a history of working well together, including how to manage both conflict and stress, as well as mutual respect so that when tumultuous times do occur, the team sticks together instead of fracturing.

Many of the teams from the eight firms included in our study met their co-founders through their respective universities. This is likely to have helped to build trust and mutual respect between the co-founders from the startups' earliest days, as they worked together on projects and assignments. The fact that these founders also studied the same curriculum created a common lexicon to refer to when making decisions and problem-solving. They also had time during their collegiate programs to build cohesion through various school-sponsored social activities, informal gatherings, and in many cases, school-sponsored business plan competitions, in which many of the teams in our study had competed in successfully.

Hawk (2016) emphasizes just how critical the relationship between members of the founding team is: “. . if you're starting a business and choosing co-founders and making your first hires, you're looking at one of the most intense relationships you're going to have in your life. It's similar to marriage." ${ }^{37}$ In the case of Kiva, two of the co-founders, Matt Flannery and Jessica Jackley, were indeed married (they have since divorced). Hawk stresses that even small decisions become much more significant in a startup setting as "issues around power and fairness are bigger, because your entire life is probably vested in the business ... living hand-to-mouth while waiting to get funded. With so much at stake, little obstacles are harder to navigate." ${ }^{38}$

Another important criterion for an investor to consider is a team's perceived adaptability. Specifically, investors want to understand a team's ability to adapt and grow as both the startup and its environment changes, including adding and removing team members as needed. According to the Bridgespan Group, "augmenting the experience and capabilities of the senior leadership team is often the most visible sign of change in organizations that are becoming more strongly managed." ${ }^{39}$ Yet, hiring and adding new team members is complex when there are so few team members to begin with; in our interviews with founders, they mentioned that each new hire's impact on their startup, in both positive and negative ways, was huge. As a result, Hawk (2016) ${ }^{40}$ advises founders to select new senior level hires carefully, ensuring adequate time for both the hiring and early evaluation process. A waiting period before sharing equity (if the SE is a for-profit firm) also gives the founding team time to evaluate how a new hire reacts when conflict arises, and how the new person works through decisions in the often highly ambiguous circumstances in which startups operate.

But what leads some teams to pivot more often and more easily than others? Strategy research has examined how teams adapt and change within large corporations and has found several important factors that are correlated with more adaptive teams. One such factor is the team's heterogeneity. It is also important to ensure there is "freshness" in the team, such that team members have varying tenure within the organization, to avoid "group think." ${ }^{41}$ In fact, research reinforces that adaptive teams often have a mix of organization tenure and differing domain expertise. ${ }^{42}$ This can be significant to a startup team, as each team member potentially brings new perspectives, knowledge bases, networks, and access to much-needed resources. 


\section{THE ROLE OF DIVERSITY}

As mentioned previously, diversity has been linked to team adaptability. We reference diversity in teams and include diversity of expertise, education, as well as diversity according to demographic descriptors used in other research (i.e., race, ethnicity, gender, sexual orientation, etc.)..$^{43}$ Drawing from the Center for Talent Innovation and McKinsey \& Company: "an increasing body of evidence [shows] that diverse teams of varying racial and ethnic makeup produce better results ... in both the for-profit and nonprofit sectors." ${ }^{\prime 4}$ This study evidences that diverse teams have stronger financial performance, less turnover, and better benefits to the customers that they serve, as well as a competitive advantage in attracting top talent. In management literature, diversity in senior management teams has long been tied to an organization's openness to strategic change and higher performance, especially when the leadership team has high levels of education and deep domain expertise. ${ }^{45}$ In published research on SEs, diversity was shown to encourage "a creative and flexible organizational culture that facilitates organizational innovation and change, which in turn produces economic and social benefits." ${ }^{46}$ So, while homogeneity in teams can lead to quicker decision-making, heterogeneity in teams, while more conflict ridden, leads to better decision outcomes ${ }^{47}$ In fact, "group heterogeneity has been associated with high levels of creativity and innovation, as well as even more comprehensive decision making, as viewpoints differ." 48

Phillips (2014) provides evidence for how social diversity, including gender, racial and ethnic differences, leads to enhanced critical thinking and decision-making on teams - as well as stronger financial performance. ${ }^{49}$ In homogeneous teams, Phillips demonstrates that team members are more likely to assume that everyone holds similar opinions; as a result, they do not process information as critically prior to group discussions: "Diversity jolts us into cognitive action in ways that homogeneity simply does not." Phillips further emphasizes: "Even simply being exposed to diversity can change the way you think ... people work harder in diverse environments both cognitively and socially. They might not like it, but the hard work can lead to better outcomes." ${ }^{50}$

In regard to financial performance, Hewlett et al. (2013) highlight that companies must innovate in order to grow and sustain themselves, and a diverse workforce is a key engine for that innovation. In fact, they found a strong correlation between companies that are diverse, innovative, and experience high market growth. ${ }^{51}$ These companies' exceptional performance is due in part to the fact that diverse employees can more easily identify with diverse end users, recognizing unfilled needs that might be overlooked by larger firms. ${ }^{52}$ Data from a McKinsey (2012) study reinforces this suggested link between cultural and gender diversity with a firm's financial performance. ${ }^{53}$ Specifically, top quartile executive boards as measured by diversity, located in the UK, US and Germany, all had superior performance by 65-95 percent, based on return on equity, in comparison to bottom quartile executive boards based on diversity. Earnings before income and tax (EBIT) were also between 29 percent and 82 percent higher for top quartile diverse boards compared to bottom quartile boards (based on diversity). ${ }^{54}$

Delving into some of the company-specific data cited in our research, we ask, how diverse were the eight founding teams? In order to answer that question, we looked at each team's educational and work experience diversity. We then assessed if the founders were more alike 
(homogeneous) or less alike (heterogeneous). ${ }^{55}$ For educational diversity, we included both undergraduate and graduate education (we did not have sufficient information to code for demographic diversity), using biographies, published research and cases, as well as LinkedIn profiles. We also accounted for the way founders spoke about the founding team's roles, a factor not heavily discussed in prior research. Indeed, our interview data suggests that teams function better if team members' roles are clearly defined and are also distinct from one another. Ideally, their scope of work complements each member's distinctive capabilities, work experience and educational background. Lastly, we noted whether the teams had more or less gender diversity.

For a summary of how the teams differed based on educational diversity, work diversity and gender, see Table 1.2. Do note that while diversity varied across teams, in every case (except for Fair Trade USA, which had a single founder) the co-founders carved out very different and complementary roles. A summary of our findings is listed in Table 1.2.

Table 1.2 Educational and experience heterogeneity

\begin{tabular}{l|l|l|l|l}
\hline & $\begin{array}{l}\text { Educational } \\
\text { Diversity }\end{array}$ & $\begin{array}{l}\text { Work } \\
\text { Experience } \\
\text { Diversity }\end{array}$ & $\begin{array}{l}\text { Complementary } \\
\text { Roles }\end{array}$ & Gender Diversity \\
\hline Embrace & Medium & High & Yes & Low \\
\hline Back to the Roots & Low & Low & Yes & Low \\
\hline Sanergy & Low & High & Yes & Medium \\
\hline d.light & Medium & High & Yes & Low \\
\hline World of Good & Medium & High & Yes & High \\
\hline Kiva & High & High & Yes & High \\
\hline Revolution Foods & Low & Low & Yes & Low \\
\hline Fair Trade USA & N/A & N/A & N/A & N/A \\
\hline
\end{tabular}

Prior to meeting in the previously mentioned Stanford course, each of Embrace's co-founders were pursuing different degrees and had very different work experiences. Jane Chen, who later became Embrace's CEO and chief fundraiser, was a first-year student in Stanford's MBA program, and had previous work experience in addressing HIV/AIDS for the Clinton Foundation. She was the only co-founder with a liberal arts degree (in psychology and economics). Linus Liang was a second-year computer science graduate student with a bachelor's degree also in computer science, who had previously co-founded several tech startups. He realized that he had a talent for operations, and that was his primary focus within Embrace. Naganand Murty had an undergraduate degree in aerospace engineering and was getting his master's degree in management science. He had previously been a management consultant. As a result, Murty oversaw the design and development of the product, as well as the startup's distributor network. The last of the four co-founders was Rahul Panicker, who was getting his $\mathrm{PhD}$ in electrical engineering from Stanford, and assumed the role of head of engineering. ${ }^{56}$ In Embrace's case, each co-founder had a distinct set of work or academic experiences that may have made it easier to delineate roles from the beginning. This team was one of the most 
diverse in education and experience in our group of social startups and had some gender diversity as well (see Table 1.3).

Table 1.3 Embrace co-founders

\begin{tabular}{l|l|l|l}
\hline Embrace & Gender & Education & \multicolumn{2}{l}{ Prior Work Experience } \\
\hline Jane Chen & F & $\begin{array}{l}\text { BA Psychology \& Economics, } \\
\text { MPA; MBA }\end{array}$ & $\begin{array}{l}\text { Program Director HIV/AIDS (Chi Heng } \\
\text { Foundation); Clinton Health Access Initiative } \\
\text { (Tanzania); Monitor Group (consulting) }\end{array}$ \\
\hline Linus Liang & M & $\begin{array}{l}\text { BA Computer Science, MS } \\
\text { Computer Science }\end{array}$ & $\begin{array}{l}\text { Co-founder, CLLZ Concepts; early employee, } \\
\text { Zynga; Program Mgr, MSFT }\end{array}$ \\
\hline Naganand Murty & M & BS/MS Engineering & Management consulting \\
\hline Rahul Panicker & M & MS \& PhD EE & $\begin{array}{l}\text { Infinera Corporation, new products group } \\
\text { (high speed optical telecom) }\end{array}$ \\
\hline
\end{tabular}

A startup with the most diverse founding team in our sample is Kiva (see Table 1.4). While it's known widely that the organization was originally co-founded by a then married couple, Jessica Jackley and Matt Flannery, two of the other co-founders included Premal Shah and Chelsa Bocci. Kiva had a diverse team with respect to gender (i.e., two female and two male co-founders), but they had an even more diverse team with respect to education and work experience. Education for the founders included a mix of liberal arts, technical and business degrees. Similarly, their work experience represented a range of positions prior to Kiva, including: human resources, computer programming, product management, and operations. Less clear is the distinction between their positions and how clearly roles were defined. However, in follow-on conversation, it appears that Shah adopted a more operational role, Flannery was the visionary, and Bocci had a variety of roles in community and marketing. Jackley was originally Kiva's Chief Marketing Officer; however, she left Kiva after six years.

Table 1.4 Kiva co-founders

\begin{tabular}{l|l|l|l}
\hline Kiva & Gender & Education & $\begin{array}{l}\text { Prior Work Experience } \\
\text { Jessica Jackley }\end{array}$ \\
\hline F & $\begin{array}{l}\text { BA Philosophy \& } \\
\text { Baobab }\end{array}$ \\
\hline Chelsa Bocci & F & BS Psychology & Immigration Specialist \& Recruiter, Barclays \\
\hline Premal Shah & M & BA Economics & Analyst, Oliver Wyman; Product Mgr, Paypal \\
\hline Matt Flannery & M & $\begin{array}{l}\text { BS Symbolic Systems; MA, } \\
\text { Philosophy }\end{array}$ & Computer Programmer, TIVO \\
\hline
\end{tabular}

Sanergy was co-founded while Ani Vallabhaneni, Lindsay Stradley and David Auerbach were at MIT, but unlike the two Stanford teams who participated in a cross-disciplinary course, the Sanergy team had limited educational diversity among the founding team as they were all MBA students. However, they had greater diversity in the area of work experience, spanning teaching and tech positions. A point of commonality, though, was that each of them had work experience that one could characterize as "social," including serving as a country manager for a dialysis clinic (Vallabhaneni), a teacher with Teach for America (Stradley), and both a teach- 
ing fellowship in China and a position as deputy chair in poverty alleviation within the Clinton Global Initiative (Auerbach) (see Table 1.5).

Table 1.5 Sanergy co-founders

\begin{tabular}{l|l|l|l}
\hline Sanergy & Gender & Education & \multicolumn{1}{l}{ Prior Work Experience } \\
\hline Ani Vallabhaneni & M & $\begin{array}{l}\text { BS Computer Science \& } \\
\text { Finance; MBA }\end{array}$ & $\begin{array}{l}\text { Co-founder, Epic Systems; Co-founder Omni } \\
\text { Studios (both tech startups); Interim Country } \\
\text { Manager, Dialysis Clinic }\end{array}$ \\
\hline Lindsay Stradley & F & $\begin{array}{l}\text { BA American Studies; } \\
\text { MBA }\end{array}$ & $\begin{array}{l}\text { Teacher, TFA; Asst. School Director, Charter } \\
\text { School; Team Lead AdWords, Google }\end{array}$ \\
\hline David Auerbach & M & $\begin{array}{l}\text { BA American Studies; } \\
\text { MBA }\end{array}$ & $\begin{array}{l}\text { Teaching Fellow, China; CGI, Poverty } \\
\text { Alleviation; Partnerships, Endeavor }\end{array}$ \\
\hline
\end{tabular}

In other startup teams - such as Revolution Foods - roles were defined more organically, through trial and error, based on what each co-founder excelled in and wanted to do. Kristin Richmond gravitated towards handling the external aspects of the enterprise, including fundraising, developing new markets and strengthening Revolution Food's visibility in the press. Kirsten Tobey, on the other hand, preferred to manage the internal operations of the company. They had very different roles, despite their similar education and work experiences (see Table 1.6). In fact, their common work experience is what drew them to found a startup together, and by both being in Haas' MBA program, they dedicated much of their coursework to the development of their startup.

Table 1.6 Revolution Foods co-founders

\begin{tabular}{l|l|l|l}
\hline Revolution Foods & Gender & Education & \multicolumn{2}{l}{ Prior Work Experience } \\
\hline Kirsten Tobey & F & BA Liberal Arts; MBA & $\begin{array}{l}\text { Teacher, Philips Andover; Program food in } \\
\text { schools - Ghana }\end{array}$ \\
\hline Kristin Richmond & F & $\begin{array}{l}\text { BA Finance and Accounting; } \\
\text { MBA }\end{array}$ & $\begin{array}{l}\text { Corp. finance, Citibank; Education in Kenya } \\
\text { and admin with indispensable schools }\end{array}$ \\
\hline
\end{tabular}

WOG's founders, Priya Haji and Siddharth Sanghvi, decided early on that Haji would take on a more "external" role, while Sanghvi would take on a more "internal" role within their startup. Haji had previous experience in social work through a nonprofit that she had founded and was already acknowledged by a number of media outlets as one of the most influential young leaders of the time, including being recognized as an Echoing Green Fellow. ${ }^{57}$ On the other hand, Sanghvi's consulting, technology and marketing experience gave him a strong foundation to handle all aspects of WOG's operations and complemented Haji's vision, charisma, and fundraising skills (see Table 1.7). In our interviews, Sanghvi described that while Haji would often get stressed about raising capital from investors or securing large retailers for the distribution of WOG's products, he would experience his highest level of anxiety if their computer servers crashed. This division of roles in both Revolution Foods and WOG created a solid foundation for the startups to grow and gave the founders the ability to span the wide 
range of roles that needed to be filled in both startups' earliest days. Hawk (2016) affirms the importance of this complementarity in founding teams:

I know one founding team that has a CEO who's extremely risk-prone. If it were only up to him, he would scale way before his company is ready. But he's paired with a great CTO who's very good at putting on the brakes. And together the two of them balance out. So, it's also knowing yourself and your personality. And then finding complementary teammates. ${ }^{58}$

Table 1.7 World of Good co-founders

\begin{tabular}{l|l|l|l}
\hline World of Good & \multicolumn{1}{l}{ Gender } & Education & \multicolumn{2}{l}{ Prior Work Experience } \\
\hline Priya Haji & F & $\begin{array}{l}\text { BA Religious Studies and } \\
\text { PreMed, MBA }\end{array}$ & Co-founder and ED, Free at Last \\
\hline $\begin{array}{l}\text { Siddharth } \\
\text { Sanghvi }\end{array}$ & M & $\begin{array}{l}\text { BA Biology, HEC Mgmt; } \\
\text { MBA }\end{array}$ & Project Mgr, Marketing Mgr, both in tech \\
\hline
\end{tabular}

Back to the Roots had the lowest diversity of those social startups in our study, given that neither founder had any meaningful prior work experience prior to launching their business, and they were both business undergraduate majors at Berkeley Haas (which is where they met) (see Table 1.8). They also are both male gendered.

Table 1.8 World of Good co-founders

\begin{tabular}{l|l|l|l}
\hline Back to the Roots & \multicolumn{1}{l}{ Gender } & \multicolumn{1}{l}{ Education } & Prior Work Experience \\
\hline Nikhil Arora & M & BA Business & None prior to startup \\
\hline Alejandro Velez & M & BA Business & None prior to startup \\
\hline
\end{tabular}

The founders of d.light, Ned Tozun and Sam Goldman, were both pursuing their MBAs, but had greater diversity in their undergraduate degrees and prior work experiences pre-MBA. Ned had more tech experience, and even founder experience, whereas Sam had been with the Peace Corps and also had large company experience at Walmart (see Table 1.9). They, of course, had no gender diversity.

Table 1.9 d.light co-founders

\begin{tabular}{l|l|l|l}
\hline d.light & Gender & Education & Prior Work Experience \\
\hline Ned Tozun & M & $\begin{array}{l}\text { BS CS (Computer } \\
\text { Science), BS Earth } \\
\text { System; MBA }\end{array}$ & $\begin{array}{l}\text { S/W Engineer, Euphonix; CTO NameWaves; CEO } \\
\text { Made for you Music }\end{array}$ \\
\hline Sam Goldman & M & $\begin{array}{l}\text { MSc; Biology \& } \\
\text { Environmental Studies; } \\
\text { MBA }\end{array}$ & $\begin{array}{l}\text { Volunteer, Peace Corps; Strategy \& Sustainability, } \\
\text { Walmart }\end{array}$ \\
\hline
\end{tabular}

In fact, the one area where there was not as much diversity across all of the teams in our study was in gender (we did not collect data on sexual orientation, and unfortunately only had two gender categories of male and female). Most teams, in fact, had a higher number of male founders, with the exception of Kiva and WOG, which had an equal mix of male and female 
co-founders. For Revolution Foods, there was also a lack of gender diversity, and in their case both founders were females.

\section{EXPANDING AND EVOLVING THE FOUNDING TEAM}

Across all eight SEs that we researched, much of the discussion around human capital highlighted the importance of having the "right team at the right time." For all eight SEs, it was challenging to balance recruiting senior leadership who were passionate about the SE's mission but also possessed the necessary skill-sets and experiences to implement the SE's deliverables. While doing "whatever it takes" is often necessary in the beginning, this "scrappiness" was most valuable when the SE was young. As the SE moved beyond its gestation stage into periods of scaling, prior expertise in particular functions became increasingly important, and often led to a "trading-out and up" of various team members. Several founders that we spoke with lamented the mistake of having too little expertise early on; others felt they had focused too much on trying to attract additional talent at the expense of losing the passion and energy that a small group of committed founding entrepreneurs can bring.

For example, the founders of Embrace thought their decision to recruit a large, inexperienced team of interns was a mistake. Given the nature of their product and the delicacy of the population they sought to help (i.e., equipping mothers of premature infants in often very rural areas with a sleeping bag-like infant warmer), they needed greater expertise in medical device development and clinical trials. In retrospect, Jane Chen felt that Embrace could have accelerated their product development process at a faster pace with more experienced early hires: "Twenty-five young people who didn't have the credibility or familiarity with the clinical studies, were not ideal for convincing potential distributors, doctors and medical facilities that the [Embrace] product was more energy efficient, safer and equally effective for newborn preemies." Most founders of our eight SEs agree that it was important to evolve the leadership and team with the changing organization, with the caveat that certain types of expertise may be more important in certain sectors, as was the case for Embrace.

However, d.light co-founder Ned Tozun also noted that experience isn't the only critical factor to growing an SE's team: "I think we probably underestimated the value of bringing on experience, but it's not just actually getting someone with deep experience. You have to get someone who's the right culture fit, who's aligned to a common vision, and actually who's still really flexible to want to learn." Hawk (2016) comments on the importance of ensuring a unified vision as the social startup expands:

when you start the first phase of hiring, it's making sure that you and your founding team have an aligned vision, so it's clear who's going to be a cultural fit. One of the things that can really break an early-stage team is bringing in the wrong person and then not having any idea how to fire them. That can be a train wreck, especially if there's equity involved. ${ }^{59}$ 
Once additional team members are hired and on board, Hawk (2016) emphasizes that leaders must continuously rearticulate the organization's vision, since it can change in a matter of a few months. ${ }^{60}$

Constant internal communication can help ensure that all employees are contributing in the same overall direction. Shah (2017) posits that leaders must build an organization's culture to achieve internal and external collaboration, since "leaders often assume that if they say it [that collaboration is important], that it will happen. It won't. Leaders need to spend the time and energy to turn the catchphrase into reality." ${ }^{11}$ To instill collaboration, leaders should openly experiment to see what configurations work best and begin talking about collaboration early, even during the hiring process. Further, rewarding collaboration and looking for ways to reinforce it through policies are important messages to send throughout the startup. ${ }^{62}$ Hawthorne (2015) expands on why this is important: "When you ask people about what it is like being part of a great team, what is most striking is the meaningfulness of the experience. People talk about being part of something larger than themselves, of being connected, of being generative." ${ }^{63}$ She argues that generative teams are particularly important for innovation, and offers three key steps leaders can take to create a generative team culture:

- Assign someone to be the "team-builder" who develops and implements activities to improve team skills such as collective dialogue and deep listening, therefore ensuring that team development doesn't fall by the wayside.

- Make sure these team development activities are consistently scheduled.

- Decide on principles for meetings that guide team members' behavior and help promote dialogue that is focused on listening.

In selecting team members, startups may also want to consider choosing candidates who demonstrate high levels of curiosity. Given the need for employees in startups to work on multiple things at once in a fast-paced and rapidly changing environment, it is important for teams to be able to deal with complexity. Chamorro-Premuzic (2014) found that having higher levels of curiosity - defined as one's "curiosity quotient" - made individuals better at handling ambiguity and complexity. It also led these individuals to seek out and acquire more knowledge over time in different domains, which helped them interpret complex situations through the lens of more familiar ones, and thus aided in problem-solving. ${ }^{64}$

\section{TRANSITIONING THE LEADERSHIP TEAM}

As SEs scale and face the question of adding more experienced leadership, another inhibitor to growth can unfortunately rest with the founders or founding team. Known as "founder's syndrome," a founder can become reticent to cede control of the firm, personalizing and perceiving the SE as an extension of him or herself. This can make it difficult for the organization to scale, as key decisions and donor relationships might reside exclusively with the founders. Research by the Bridgespan Group identifies four options for transitioning founding teams, including: retaining a meaningful role for the founder; retaining a lesser role for the founder; an involuntary break (i.e., dismissal); or an amicable clean break. ${ }^{65}$ Figure 1.1 shows the per- 
centage breakdown for each transition, specifically within the nonprofit space. The majority of founder transitions involve an amicable break, wherein the founder stays on in a different capacity within the organization.

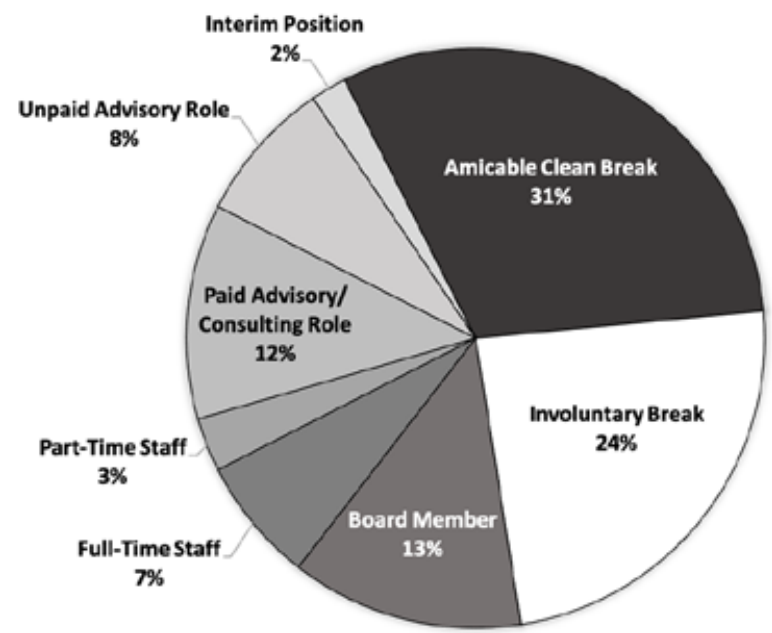

Figure 1.1 Four types of founder transitions

Clearly, identifying when to start a leadership transition is critical for the well-being of the SE and the beneficiaries it serves. Tuomala et al. $(2018)^{66}$ provide a list of signals that indicate it may be time for a change in leadership:

- The founder is slowing down due to poor health or lack of energy.

- The founder has more energy for outside projects than for stewarding the organization.

- Staff support for the founder is declining.

- The founder is increasingly in conflict with the organization's board of directors.

- The organization has grown significantly without any change to organizational structure.

- The organization's core funding base has stalled or is shrinking.

- The organization has reached a stage where it requires skills that the founder and senior staff lack and are not developing.

While the aforementioned research suggests that founders should maintain a role in the organization, it also acknowledges the inherent difficulty in transitioning leadership. For example, founders sometimes choose to stay for the wrong reasons. They may not know what to do next, their identities might be inextricably tied to the startup, or they may believe that the organization cannot survive without them. ${ }^{67}$ Tuomala emphasized that even when founders want to stay for the right reasons, the journey can be complex, and the organization's board of directors often rightly worries about the real and perceived confusion around roles and responsibilities that an extended stay might create. Tuomala further suggests that when such transitions are necessary, the best way to execute them is to maintain a role for the founder(s) in the company, rather than a complete break (either amicable or involuntary). As shown in 
Figure 1.2 below, organizations tend to be more successful when the founder stays on in some capacity. ${ }^{68}$

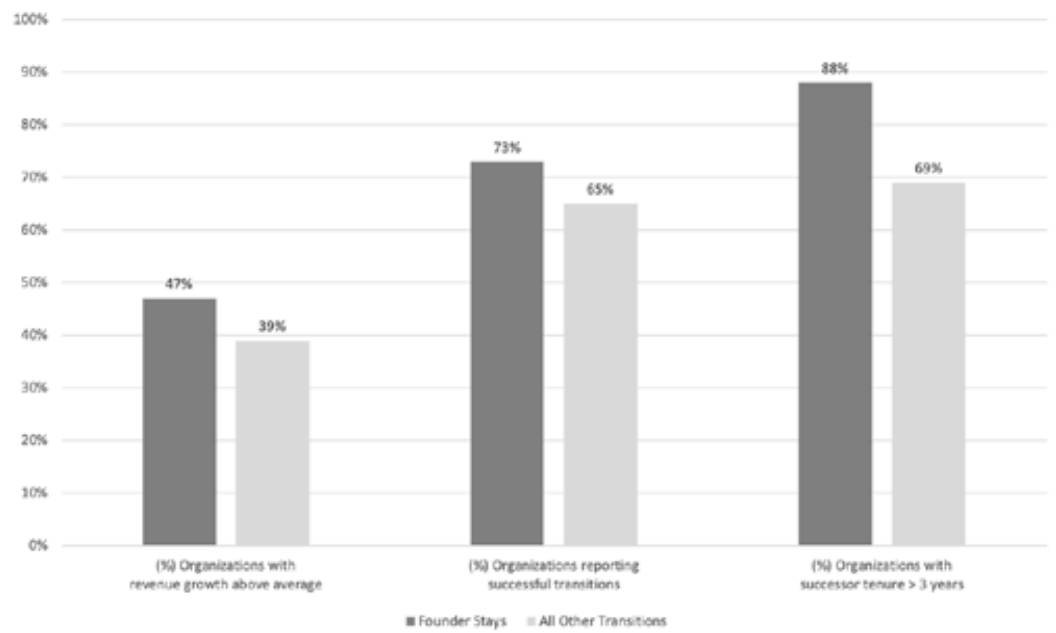

Figure 1.2 Measuring success when the founder stays in the company

In our research, many of the founders of their respective organizations are still managing and leading their social startups. The exceptions are WOG, which was sold to eBay in 2010, Embrace and Kiva. When WOG was sold, five years post-founding, ${ }^{69}$ Sanghvi did stay on with eBay for a few years. Haji found another startup, but suddenly passed away in 2014. As for Embrace, its nonprofit arm has now merged with Thrive Networks. Kiva has had a series of transitions post-founding: while two of the original co-founders, Jackley and Flannery, are no longer with the nonprofit, other founders, such as Shah and Bocci, continued to be involved at the highest levels of Kiva, with Shah as the CEO and Bocci as the Chief Community Officer. As of this writing, now only Bocci remains at Kiva.

In closing, what are our key takeaways for having a successful early startup and team?

- When founding, think of clear roles for each co-founder, ensuring that your team is diverse in expertise, education and experience.

- Trust is central to performance amongst diverse teams. Ensuring that the team congeals instead of fracturing requires a focused, continual effort on organizational alignment and communication.

- Hire slowly and build in evaluation periods to release organizational misfits more quickly. If new team members don't align with the team, have difficulty managing ambiguity, lack passion for the SE's mission, or don't want to continually learn and adapt, they might be misfits for the startup. If so, best to release them quickly as they will likely have an outsized negative impact on your startup's performance. But also remember that new team members bring fresh perspectives, which may be required in order for the startup to pivot and grow. 
- Within social startups, commitment to its purpose and mission is a key criterion when hiring.

- If and when a member of the founding team must leave, it is best to find a new role for the co-founder, retaining some level of engagement, as removing a founder altogether brings too much risk to the organization.

A few of the SEs in our study brought in external CEOs who had more experience, after the five-year mark, only to return the social startup back to its original founders. In these situations, the new CEO's performance, fit, or adaptability did not meet expectations and turned out to be misaligned with what the high-growth SE needed in the long term.

\section{CASE STUDY}

SANERGY

As dawn broke across the morning skies above Nairobi, Kenya, David Auerbach, Lindsay Stradley and Ani Vallabhaneni - the three principal co-founders of Sanergy - met for an early morning meeting to reflect upon the startup's achievements over the past five years and to ponder the opportunities and challenges that lay ahead. The idea for Sanergy - the blending of the words "sanitation" and "energy" - emerged out of a business plan project when the three were MBA classmates at MIT Sloan. They had won numerous awards and fellowships for their startup idea, including the MIT 100K Entrepreneurship Competition. They were also awarded numerous fellowships, including recognition from renowned organizations such as Echoing Green, Draper Richards Kaplan and Ashoka. After two rounds of funding and 251 employees, the founders felt confident about the future of their venture.

Yet the founders understood the global need for better sanitation solutions, especially in many of the poorest regions of the world. According to the United Nations, 2.5 billion people, almost 40 percent of the global population, lack access to basic sanitation, including eight million of the estimated ten million people who live in Kenya's multiple urban slums. These poor sanitation conditions have contributed to the death of an estimated 1.6 million children worldwide each year.

The startup's original business plan highlighted the three key components of the startup's business: (1) a dense network of micro-franchised small-scale sanitation centers located on every block of the slums; (2) a low-cost containerized waste collection in-

\section{Figure 1.3}

SANERGY logo and sustainable sanitation cycle

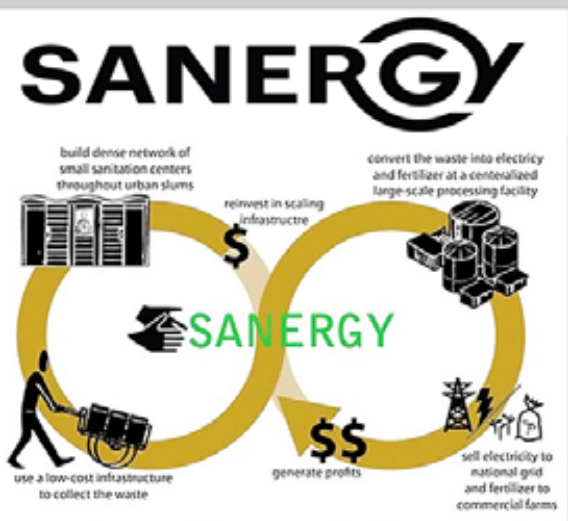

a sustainable sanitation cycle 
frastructure to easily transport the waste; and (3) a centralized processing facility to efficiently convert the waste into electricity, which is then sold to the national grid, and high-quality organic fertilizer, which is sold to farms, tapping into a potential \$177 million market in Kenya. At each step, the startup sought to create jobs, opportunity and profit, while simultaneously addressing serious social and economic needs.

But, how diverse was the original founding team? The three founders all received their MBAs from MIT Sloan. While their graduate degrees were the same, their pre-MBA work experiences were a bit more heterogeneous. Auerbach had taught English in China and was also the deputy chair for poverty alleviation for the 2005-2006 Clinton Global Initiative. Stradley had worked for Teach for America in New Orleans and had set up a charter school after Hurricane Katrina. Stradley then went on to work at tech giant Google as a team lead in its core product area: AdWords. Vallabhaneni had turned around a chain of dialysis clinics in the Philippines. Curiously, none of them had worked in Kenya or in sanitation prior to founding Sanergy.

By December 2015, Sanergy had 614 Fresh Life toilets in operation that were being used 31,355 times per day and had already collected more than 7,900 metric tons of waste. Additionally, Sanergy had created 779 jobs, including team members, Fresh Life Operators, and attendants - with 60 percent of staff coming from the informal settlements that it served, significantly altering the composition of Sanergy's employee base. Near the end of 2015, 93 percent of Sanergy's 251 employees (called "teammates") across its eight key departments (i.e., sales, marketing, operations, toilet manufacturing, waste management, processing, technical, and administration) were Kenyans, with 40 percent of them under the age of 25. Auerbach believed that having such a strong Kenyan presence was a key success factor. He explained:

We've worked hard to establish a Kenyan leadership team to be the ones running country operations on a daily basis. Our managers have a strong intuitive understanding of the cultural context, which is critical for solving problems and which our expat teammates will never have at the same level. At the same time, most of our funding, media, and R\&D partnerships come from international organizations and therefore we've built an organization of expats and Kenyans who are adept at working with these stakeholders.

Included in Sanergy's team was a seven-member government relations department, made up entirely of Kenyans. This team dealt with the Kenyan government at both the municipal and national levels on a regular basis and had recently stepped up its efforts as Sanergy sought to increase the number of toilet sites in public schools as part of a Gates Foundation grant. Acumen, another key investor, was also helpful in introducing the Sanergy team to its network of government officials, given Acumen's Kenya-based office.

As the number of Sanergy employees grew, the importance of internal communications also increased. Every quarter, Sanergy would hold an "all-hands" meeting with the co-founders, open to everyone from the waste collectors to the corporate officers. At this meeting, an "employee of the quarter" would be honored, business metrics were 
discussed, and updates were given. Sanergy found transparency with its employees to be an important element of its culture.

As the founders set out to plan the future of Sanergy, they reflected on the history of the venture and the tactics that had allowed them to succeed in scaling an SE in a country that none of them had ever even been to before.

\section{CASE QUESTIONS}

In thinking about Sanergy's journey from the beginning to where it is now:

1. What components of the founding team made it more likely to succeed than not?

2. How has the team changed since its founding?

*For more information, see the Berkeley Haas Case Series titled Sanergy: Tackling Sanitation in Kenyan Slums.

\section{NOTES}

1. “Elon Musk.” Wikipedia, en.wikipedia.org/wiki/Elon_Musk. Accessed 7 April 2019.

2. “Steve Jobs.” Wikipedia, en.wikipedia.org/wiki/Steve_Jobs. Accessed 7 April 2019.

3. Lechler, Thomas. "Social Interaction: A Determinant of Entrepreneurial Team Venture Success." Small Business Economics, vol. 16, no. 4, 2001, pp. 263-78, doi:10.1023/A:1011167519304. Accessed 8 April 2019.

4. Gartner, William, Kelly G. Shaver, Elizabeth Gatewood, and Jerome A. Katz. "Finding the Entrepreneur in Entrepreneurship." Entrepreneurship Theory and Practice, vol. 18, no. 3, 1994, pp. 5-9, doi:10.1177/ 104225879401800301. Accessed 8 April 2019.

5. Teams have been identified as "two or more individuals who jointly establish and actively participate in a business in which they have an equity (financial) interest". We used this definition for all types of SEs, nonprofit, for-profit or hybrid.

6. For more details on how we measured growth by impact, revenue and employees, see Appendix 1.1.

7. Embrace Innovations. www.embraceinnovations.com/. Accessed 8 April 2019.

8. Back to the Roots. www.backtotheroots.com. Accessed 8 April 2019.

9. Sanergy. www.sanergy.com. Accessed 8 April 2019.

10. d.light. www.dlight.com. Accessed 8 April 2019.

11. Brewer-Hay, Richard. “Introducing Worldofgood.com.” eBay, 3 September 2008, www.ebayinc.com/stories/ news/introducing-worldofgoodcom. Accessed 21 November 2019.

12. Kiva. www.kiva.org. Accessed 8 April 2019.

13. Revolution Foods. www.revolutionfoods.com. Accessed 8 April 2019.

14. Fair Trade Certified. www.fairtradecertified.org. Accessed 8 April 2019.

15. “Paul Rice.” Wikipedia, en.wikipedia.org/wiki/Paul_Rice. Accessed 8 April 2019.

16. “Georges Doriot.” Wikipedia, en.wikipedia.org/wiki/Georges_Doriot. Accessed 8 April 2019.

17. Bygrave, William, and Andrew Zacharakis. The Portable MBA in Entrepreneurship. 4th edn, Wiley, 2004, Hoboken, NJ. 
18. Doerr has made many notable investments including: Google, Facebook, Amazon and, more recently, Indiegogo.

19. “John Doerr." Kleiner Perkins, www.kleinerperkins.com/people/john-doerr. Accessed 8 April 2019.

20. Malone, Michael. “John Doerr's Startup Manual.” Fast Company, 28 February 1997, www.fastcompany.com/ 28223/john-doerrs-startup-manual. Accessed 8 April 2019.

21. Better Ventures. www.better.vc. Accessed 8 April 2019.

22. Walske, Jennifer, and Laura Tyson. "Better Ventures: Backing Entrepreneurs Building a Better World." Harvard Business Review, 1 January 2017. Berkeley Haas Case Series.

23. Ibid.

24. Boyd, David, and David Gumpert. "Coping with Entrepreneurial Stress." Harvard Business Review, vol. 61, no. 2, 1983, pp. 44-59.

25. Adebowale, Akande. "Coping with Entrepreneurial Stress: A Nigerian Case Study." Leadership \& Organization Development Journal, vol. 13, no. 2, 1992, pp. 27-32, doi:10.1108/01437739210009608.

26. Cooper, Arnold, and Albert Bruno. "Success among High-Technology Firms." Business Horizons, vol. 20, no. 2, 1977, pp. 16-22, doi:10.1016/0007-6813(77)90096-9.

27. Eisenhardt, Kathleen, and Claudia Schoonhoven. "Organizational Growth: Linking Founding Team, Strategy, Environment, and Growth among U.S. Semiconductor Ventures, 1978-1988." Administrative Science Quarterly, vol. 35, no. 3, 1990, pp. 504-29.

28. Hambrick, Donald, Theresa Seung Cho, and Ming-Jer Chen. “The Influence of Top Management Team Heterogeneity on Firms' Competitive Moves.” Administrative Science Quarterly, vol. 41, no. 4, 1996, pp. 659-84, doi:10.2307/2393871.

29. Cooper, Arnold, and Catherine Daily. "Entrepreneurial Teams." Entrepreneurship 2000, edited by D.L. Sexton and R.W. Smilor, Upstart Publishing Company, 1996, Carrolton, TX, pp. 127-50.

30. Stanford d.school. dschool.stanford.edu. Accessed 17 April 2019.

31. It is not uncommon for some attrition to occur in social startups founded within the collegiate environment, as some students will take jobs postgraduation and no longer remain active with the firm.

32. Walske, Jennifer, and Laura Tyson. "Social Entrepreneurs: Say Yes." Stanford Social Innovation Review, 2 October 2014, ssir.org/articles/entry/social_entrepreneurs_say_yes.

33. Zhuo, Tx. "5 Qualities VCs Look for in Your Startup Team.” Entrepreneur, 8 January 2015, www .entrepreneur.com/article/241441. Accessed 17 April 2019.

34. Curşeu, Petru, and Sandra Schruijer. "Does Conflict Shatter Trust or Does Trust Obliterate Conflict? Revisiting the Relationships Between Team Diversity, Conflict, and Trust.” Group Dynamics: Theory, Research, and Practice, vol. 14, no. 1, 2010, pp. 66-79, doi:10.1037/a0017104.

35. Hartigan, Pamela, and Charmian Love. "The Power of Unreasonable Teams." Stanford Social Innovation Review, Winter 2013, www.ssir.org/articles/entry/the_power_of_unreasonable_teams. Accessed 17 April 2019.

36. Lechler, Thomas. "Social Interaction: A Determinant of Entrepreneurial Team Venture Success." Small Business Economics, vol. 16, no. 4, 2001, pp. 263-78, doi:10.1023/A:1011167519304. Accessed 8 April 2019.

37. Hawk, Steve. "How to Build a Better Startup Team." Insights by Stanford Business, 14 December 2016, www .gsb.stanford.edu/insights/how-build-better-startup-team. Accessed 17 April 2019.

38. Ibid. 
39. Stid, Daniel, and Jeffrey Bradach. "Strongly Led, Under-Managed." The Bridgespan Group, 1 August 2008, www.bridgespan.org/insights/library/organizational-effectiveness/strongly-led-under-managed. Accessed 17 April 2019.

40. Hawk, Steve. "How to Build a Better Startup Team." Insights by Stanford Business, 14 December 2016, www .gsb.stanford.edu/insights/how-build-better-startup-team. Accessed 17 April 2019.

41. Wiersema, Margarethe, and Karen Bantel. “Top Management Team Demography and Corporate Strategic Change." Academy of Management Journal, vol. 35, no. 1, 1992, pp. 91-121, doi:10.2307/256474. Accessed 17 April 2019.

42. Eisenhardt, Kathleen, and Claudia Schoonhoven. "Organizational Growth: Linking Founding Team, Strategy, Environment, and Growth among U.S. Semiconductor Ventures, 1978-1988.” Administrative Science Quarterly, vol. 34, no. 3, 1990, pp. 504-29.

43. Cho, Sangmi, Ahraemi Kim, and Michelle E. Mor Barak. "Does Diversity Matter? Exploring Workforce Diversity, Diversity Management, and Organizational Performance in Social Enterprises." Social Work and Policy, vol. 11, no. 3, October 2017, pp. 193-204, doi:10.1111/aswp.12125. Accessed 17 April 2019.

44. Brennan, Molly. "Five Ways to Build Diverse, Inclusive Leadership Teams." Stanford Social Innovation Review, 13 February 2015, www.ssir.org/articles/entry/five_ways_to_build_diverse_inclusive_leadership _teams. Accessed 17 April 2019.

45. Wiersema, Margarethe, and Karen Bantel. “Top Management Team Demography and Corporate Strategic Change." Academy of Management Journal, vol. 35, no. 1, March 1992, pp. 91-121, doi:10.2307/256474. Accessed 17 April 2019.

46. Cho, Sangmi, Ahraemi Kim, and Michelle E. Mor Barak. "Does Diversity Matter? Exploring Workforce Diversity, Diversity Management, and Organizational Performance in Social Enterprises." Social Work and Policy, vol. 11, no. 3, 2017, pp. 193-204, doi:10.1111/aswp.12125. Accessed 17 April 2019.

47. Hambrick, Donald, Theresa Seung Cho, and Ming-Jer Chen. "The Influence of Top Management Team Heterogeneity on Firms' Competitive Moves.” Administrative Science Quarterly, vol. 41, no. 4, 1996, pp. 659-84, doi:10.2307/2393871.

48. Ibid.

49. Phillips, Katherine. "How Diversity Makes Us Smarter.” Scientific American, 16 September 2014, www .scientificamerican.com/article/how-diversity-makes-us-smarter. Accessed 17 April 2019.

50. Ibid.

51. Hewlett, Sylvia Ann, Melinda Marshall, and Laura Sherbin. "Innovation, Diversity, and Market Growth." Center for Talent Innovation, 2013, www.talentinnovation.org/_private/assets/IDMG-ExecSummFINAL -CTI.pdf. Accessed 17 April 2019.

52. Ibid.

53. Devillard, Sandrine, W., Wieteke Graven, Emily Lawson, Renée Paradise and Sandra Sancier-Sultan. "Women Matter 2012: Making the Breakthrough." McKinsey \& Company, March 2012, www.mckinsey.com/ / media/McKinsey/Business\%20Functions/Organization/Our\%20Insights/Women\%20matter/Women _matter_mar2012_english\%20(1).ashx. Accessed 21 November 2019.

54. Ibid.

55. Solanas, Antonio, R.M. Selvan, J. Navarro, and D. Leiva. “Some Common Indices of Group Diversity: Upper Boundaries." Proceedings of Measuring Behavior 2012, August 2012, pp. 412-13, www.measuringbehavior .org/files/2012/ProceedingsPDF(website)/Posters/Solanas_et_al_MB2012.pdf. Accessed 17 April 2019. 
56. Chu, Michael, David E. Bloom, and Alison Berkley Wagonfeld. "Embrace." Harvard Business School Publishing, 18 July 2013. Harvard Business School Case Series 9-814-001.

57. “Echoing Green Fellowship Programs.” Echoing Green, www.echoinggreen.org/fellowship. Accessed 12 March 2019.

58. Hawk, Steve. "How to Build a Better Startup Team.” Insights by Stanford Business, 14 December 2016, www .gsb.stanford.edu/insights/how-build-better-startup-team. Accessed 17 April 2019.

59. Ibid.

60. Ibid.

61. Shah, Pratichi. "Building Real Collaboration into Your Organization." Stanford Social Innovation Review, 24 May 2017, www.ssir.org/articles/entry/building_real_collaboration_into_your_organization. Accessed 17 April 2019.

62. Ibid.

63. Hawthorne, Margaret. "Cultivating and Sustaining Generative Teams." Stanford Social Innovation Review, 4 June 2015, www.ssir.org/articles/entry/cultivating_and_sustaining_generative_teams. Accessed 17 April 2019.

64. Chamorro-Premuzic, Tomas. "Curiosity Is as Important as Intelligence." Harvard Business Review, 27 August 2014, www.hbr.org/2014/08/curiosity-is-as-important-as-intelligence. Accessed 17 April 2019.

65. Tuomala, Jari, Donald Yeh, and Katie Smith Milway. “Making Founder Successions Work.” Stanford Social Innovation Review, Spring 2018, ssir.org/articles/entry/making_founder_successions_work. Accessed 17 April 2019.

66. Ibid.

67. Ibid.

68. Ibid.

69. "World of Good Sells Brand and Assets to eBay, Wholesale Division to GreaterGood." TechCrunch, 25 February 2010, www.techcrunch.com/2010/02/25/ebay-world-of-good. Accessed 17 April 2019. 


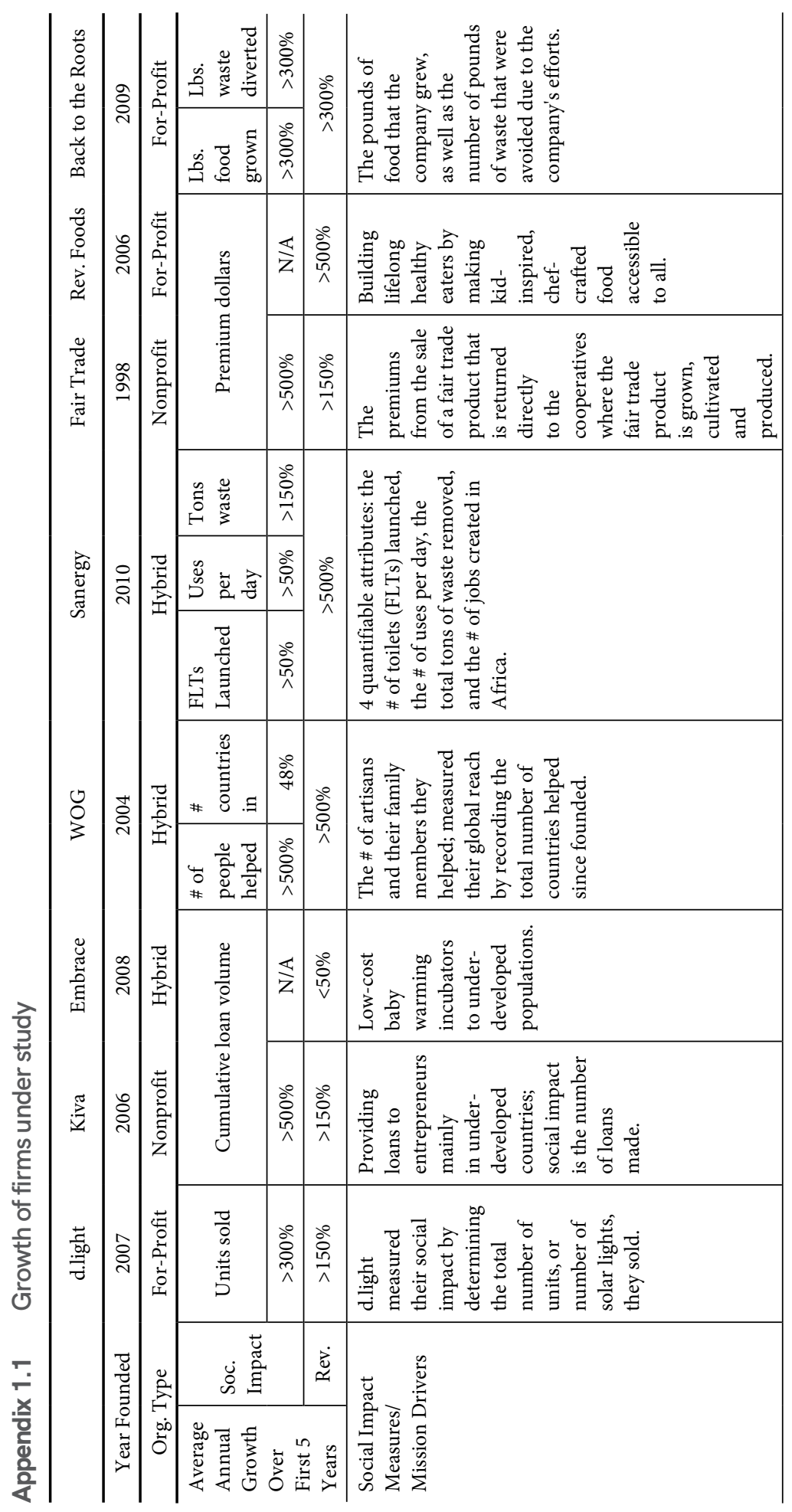




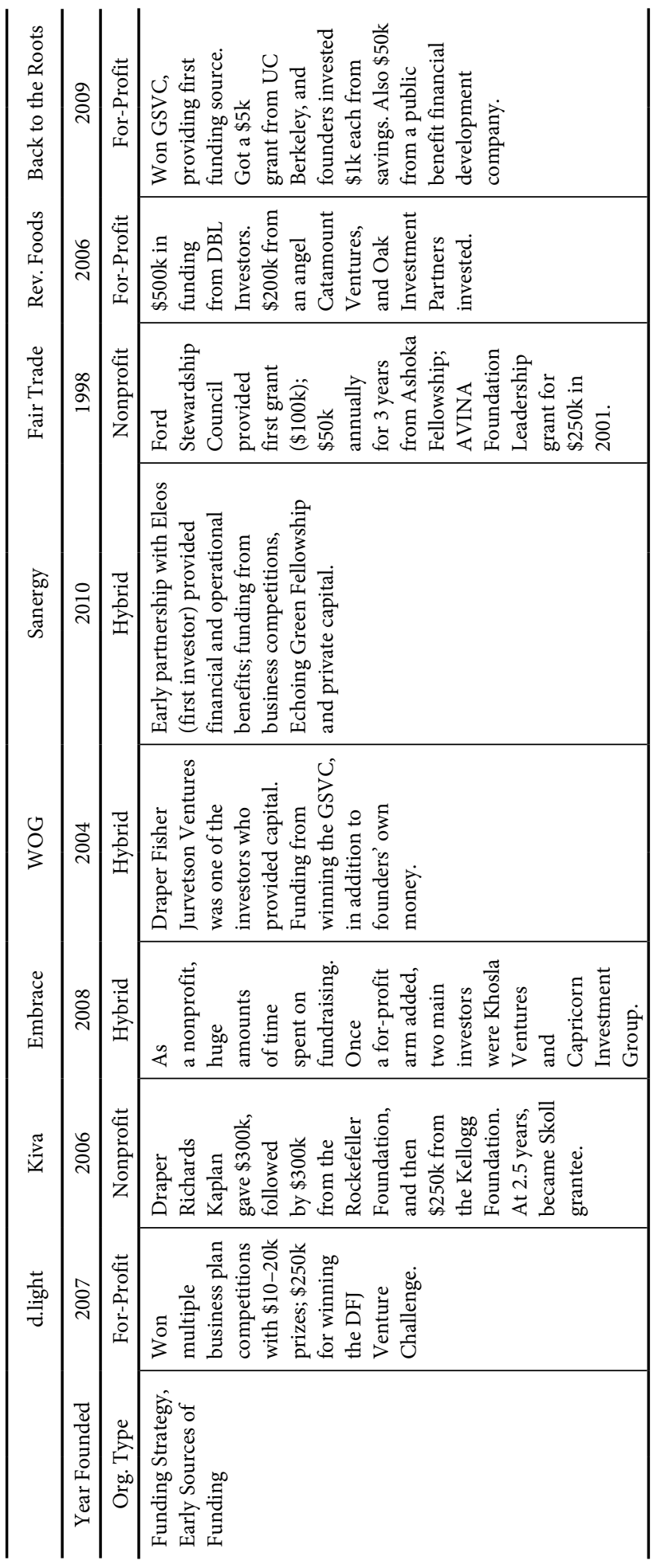

